\title{
Entre a proteção e os fundamentos dos direitos humanos: críticas a algumas dificuldades hermenêuticas do positivismo jurídico
}

\author{
Between protection and the foundations of human rights: criticism to some \\ hermeneutical difficulties of legal positivism
}

\author{
Rômulo Gubert de Mello Brum* \\ Rafael Fonseca Ferreira*
}

\section{Resumo}

\begin{abstract}
A partir de um recorte temático, o presente artigo visa elaborar uma breve contribuição: a de que a proteção dos direitos humanos não prescinde do problema de sua fundamentação. De maneira mais incisiva, procura demonstrar que somente se pode compreender o que sejam, ou não, tais direitos na medida em que se resgatam seus fundamentos insculpidos não somente através de documentos jurídicos/políticos, mas ao longo do curso histórico da humanidade. O trabalho é dividido em dois tópicos: o primeiro deles é dedicado a delimitar as dificuldades impostas à afirmação cunhada por Norberto Bobbio de que o desafio dos direitos humanos, contemporaneamente, é sua proteção e, somente em segundo plano, seu fundamento, analisando ainda as limitações de uma perspectiva estatalista do Direito para a abertura constitucional aos tratados internacionais de proteção à dignidade humana. A segunda parte visa esboçar uma alternativa teórica capaz de enfrentar satisfatoriamente tais dificuldades, especialmente com os aportes da teoria do Direito como integridade de Ronald Dworkin e da hermenêutica filosófica de Hans-Georg Gadamer, com o objetivo de demonstrar a imprescindibilidade da ideia de fundamentação como elo entre texto constitucional e tradição dos direitos humanos. A abordagem desenvolvida se sucede com as contribuições da hermenêutica filosófica.
\end{abstract}

Palavras-chave: Constituição. Integridade. Direitos humanos.

\section{Abstract}

From a thematic clipping the present article aims to make a brief contribution: that the protection of human rights does not dispense with the problem of its foundation. In a more incisive way, it seeks to demonstrate that one can only understand what these rights are or not, insofar as their inscribed foundations are rescued not only through legal / political documents but throughout the course of history of humanity. The paper is divided into two topics: the first one dedicated to delimite the difficulties imposed by Norberto Bobbio's assertion that the challenge of human rights is at the same time its protection, and secondly its foundation, analyzing the limitations of a Stateist perspective of the law for constitutional opening to international treaties for the protection of human dignity. The second part aims to outline a theoretical alternative capable of satisfactorily addressing such difficulties, especially with the contributions of the Law as the integrity of Ronald Dworkin and Hans-Georg Gadamer's philosophical Hermeneutics, with the objective of demonstrating the indispensability the idea of grounding as a link between constitutional text and tradition of human rights. The approach developed follows the contributions of philosophical hermeneutics.

Keywords: Constitution. Integrity. Human rights

\section{Introdução}

A discussão acerca da proteção necessária aos direitos humanos contemporaneamente, embora não seja nenhuma novidade, continua suscitando problemas para os quais ainda não houve resposta

Mestre em Direito e Justiça Social pela Universidade Federal do Rio Grande - FURG. Rio Grande - RS - Brasil. E-mail: romulo_gmb2007@ hotmail.com

- Doutor e Mestre em Direito Público pela Universidade do Vale do Rio dos Sinos - UNISINOS. Professor dos cursos de graduação e pósgraduação (mestrado) em Direito na Universidade Federal do Rio Grande. Rio Grande - RS - Brasil. E-mail: rafaelferreira@furg.br. 
consensual por parte da comunidade jurídica. Como consequência, diversas são as teorizações que procuram fornecer uma resposta, de acordo com as peculiaridades das respectivas sociedades sobre as quais se dedicam, ao aproximar a substancialidade oriunda do Direito Internacional pós Segunda Guerra Mundial dos movimentos constitucionais dela decorrentes - quer pelos diferentes documentos internacionais que versam sobre o assunto, quer pelas próprias Constituições locais que procuram dialogar com a história na construção de um projeto de sociedade democrático.

Nesse âmbito, o presente trabalho pretende problematizar uma afirmação bastante conhecida mas pouco questionada no espaço doutrinário - de que o desafio colocado hoje para os direitos humanos não é o problema de sua fundamentação, mas sim o de sua proteção. A proposição advém de um texto oriundo de uma conferência proferida pelo jurista e filósofo político italiano Norberto Bobbio, em Turim, no ano de 1967 e, posteriormente, publicado na obra "A Era dos Direitos" sob o título "Presente e Futuro dos Direitos do Homem". O que se pretende, neste artigo, não é, todavia, afirmar o equívoco do teórico italiano a partir de uma análise do momento histórico no qual estava situado, mas sim apontar que o constitucionalismo brasileiro contemporâneo precisa superar tal separação entre fundamentos e proteção dos direitos humanos caso se pretenda dar conta do que significou o constitucionalismo pós Segunda Guerra Mundial, introduzido no país com a Constituição Federal de 1988.

Como hipótese, pretende-se mostrar que uma correta interpretação do Direito (e dos direitos humanos e fundamentais) requer uma reconstrução da moralidade política de uma comunidade a partir de sua história institucional, de modo que a compreensão que se pretenda adequada não pode prescindir do resgate da tradição hermenêutica subjacente a cada um deles. Logo, o sentido dos direitos humanos e fundamentais torna imprescindível a tarefa de dialogar acerca de seus fundamentos para que a interpretação não se torne arbitrária pela ausência de uma prestação de contas hermenêutica.

Quanto à abordagem empregada, o trabalho se vale das contribuições da hermenêutica filosófica de Hans-Georg Gadamer, para quem o problema da compreensão se sucede por uma perspectiva intersubjetiva, na qual há um compartilhamento de sentido entre os sujeitos. É por meio desse compartilhamento de sentido que se pode falar em diálogo, estruturado através da dinâmica da pergunta e da resposta, de modo que a pergunta consiste na colocação em suspenso dos preconceitos do intérprete, enquanto diferentes projetos de sentido vão sendo contrastados, até o desmascaramento daqueles que se mostram incompatíveis com aquilo que se investiga. A compreensão, portanto, pressupõe a capacidade de o objeto da investigação "dizer" algo, isto é, provocar o sujeito a rever suas pré-concepções, ocasionando uma dialogicidade cujo resultado já não é uma atribuição de sentido arbitrária ao investigado pelo investigador, mas uma proposição que reconhece a singularidade daquilo que é investigado. Para os fins propostos nesta discussão, o caminho dialógico permite que o Direito deixe de ser um ramo do conhecimento eminentemente dedicado a descrição de provimentos normativos para se tornar um campo também preocupado com a exigência de correção da interpretação jurídica, uma vez que somente a textualidade da lei, ou dos tratados internacionais, não é suficiente para compreender o que significa propriamente o conteúdo de um direito humano ou fundamental, pois, por trás de cada um dos mencionados documentos, há princípios de moralidade política que devem ser resgatados pelo intérprete para que o sentido daquilo que está no texto jurídico se mostre por meio daquilo que lhe é próprio.

A exposição desta investigação se divide em dois tópicos. O primeiro deles trata de aprofundar os desdobramentos da afirmação de Bobbio. Se, de um lado, é possível se cogitar um certo consenso quanto a necessidade de efetivação dos direitos humanos; por outro, saber o que efetivamente consiste essa proteção, ou qual seja o âmbito de incidência de um determinado direito, é questão bem mais complexa e controversa. Não obstante, a própria estruturação de um ordenamento jurídico em forma piramidal parece ter sido uma das principais heranças do positivismo jurídico normativista que impulsionaram uma cisão entre direitos humanos e fundamentais em termos de validade e eficácia. Especificamente no contexto brasileiro, acredita-se existir uma diferença "genética" entre aqueles tratados internacionais de direitos humanos incorporados e equiparados a normas constitucionais por força do $\S 3^{\circ}$ do art. $5^{\circ}$ da Constituição 
Federal e aqueles que somente ingressam no ordenamento jurídico nacional por meio do $\S 2^{\circ}$ do mesmo dispositivo, mas, dessa vez, com força normativa somente supralegal.

O segundo tópico trata de apresentar a abordagem pela qual se pretende provar não ser possível realizar uma ruptura estrutural entre fundamentos e aplicação dos direitos humanos. Para tanto, vale-se da teoria do Direito como integridade de Ronald Dworkin e da hermenêutica filosófica de Hans-Georg Gadamer como os paradigmas norteadores de uma teoria do Direito comprometida com a realização democrática do constitucionalismo, o qual tampouco pode ser visto como um fenômeno desconexo do cenário internacional de firmação de um compromisso de proteção da dignidade humana. Como se pretende evidenciar, não há uma diferença de substância entre os direitos fundamentais incorporados pelo texto constitucional brasileiro (e os tratados internacionais equiparados por força do referido $\S 3^{\circ}$ do art. $5^{\circ}$ da Constituição Federal) e os direitos humanos. Ambos implicam-se mutuamente no processo de interpretação/aplicação do Direito.

\section{Por que a compreensão dos direitos humanos pelo paradigma positivista é problemática?}

Os desafios impostos a uma teorização acerca da proteção dos direitos humanos não são poucos. Norberto Bobbio, em sua conhecida obra "A Era dos Direitos", tinha dimensão de tais dificuldades ao reconhecer que os direitos humanos não são algo "dado", mas historicamente condicionados, de modo que nascem quando as circunstâncias históricas assim permitem, o mesmo valendo para a extinção daquilo que, em outros contextos, também era entendido como um direito e, posteriormente, deixou de sê-lo (BOBBIO, 1992, p. 5). Tendo essa premissa em consideração, não é difícil compreender a angústia proposta pelo autor italiano: os "Direitos do Homem" (essa é a expressão por ele empregada) encontramse continuamente sujeitos a avanços, mas principalmente a retrocessos, conforme o tempo e o lugar em que estejam situados. Sua proteção, portanto, se torna um problema central no plano teórico, de modo que a questão relativa ao fundamento, embora não esteja extinta, passa para o segundo plano (BOBBIO, 1992, p. 25).

Entretanto, o problema não estaria resolvido por conta de alguma espécie de fundamento último para os direitos humanos, ou seja, uma razão tão bem elaborada a ponto de se tornar irresistível a qualquer espécie de oposição. Tal noção, aliás, era alvo de duras críticas por parte do autor, para quem ela acabava criando mais dificuldades do que solucionando. Para Bobbio (1992, p. 16), não é a exigência de um valor natural último aquilo que funda um consenso sobre a necessidade de proteção da humanidade, embora essa tenha sido a grande ambição do jusnaturalismo na perspectiva do teórico italiano. Esse consenso, ao invés disso, teria por ponto de estofo a própria Declaração Universal de Direitos Humanos:

\footnotetext{
Entende-se que a exigência do 'respeito' aos direitos humanos e às liberdades fundamentais nasce da convicção, partilhada universalmente, de que eles possuem fundamento: o problema do fundamento é ineludível. Mas, quando digo que o problema mais urgente que temos de enfrentar não é o problema do fundamento, mas o das garantias, quero dizer que consideramos o problema do fundamento não como inexistente, mas como - em certo sentido - resolvido, ou seja, como um problema com cuja solução já não devemos mais nos preocupar. Com efeito, pode-se dizer que o problema do fundamento dos direitos humanos teve sua solução atual na Declaração Universal dos Direitos do Homem aprovada pela Assembléia-Geral das Nações Unidas, em 10 de dezembro de 1948.

A Declaração Universal dos Direitos do Homem representa a manifestação da única prova através da qual um sistema de valores pode ser considerado humanamente fundado e, portanto, reconhecido: e essa prova é o consenso acerca da sua validade (BOBBIO, 1992, p. 22).
}

Situando o fundamento na própria Declaração Universal de Direitos Humanos, Bobbio (1992) procura deslocar o debate do campo da filosofia para situá-lo no Direito e, conforme ele próprio, mais amplamente no da política. Esse redirecionamento do debate é, na verdade, a tentativa que o autor italiano faz de solucionar as divergências teóricas acerca da validade dos direitos humanos por meio de uma convergência a partir de seus fundamentos, a qual seria dada pela própria Declaração de 1948. Em 
outras palavras, por ser tal questão filosófica resolvida de antemão, ao Direito, ou à política, não caberia mais a indagação acerca do fundamento, mas somente quanto aos meios aptos a concretizar os valores insculpidos na Declaração Universal dos Direitos Humanos. Uma interpretação que é reforçada quando se constata que o texto em que o autor italiano realiza tal proposição teve origem em uma conferência por ele proferida em Turim, no ano de 1967, somente 19 anos após a Declaração de 1948, fenômeno jurídico relativamente novo e que, portanto, naturalmente seria ainda objeto de muitos debates acerca de sua validade no interior dos ordenamentos jurídicos nacionais.

Embora se possa considerar como de boa intenção a proposta do autor italiano, ela suscita diferentes tipos de problemas, os quais se passará a debater no restante deste tópico. É cabível se perguntar se é possível uma separação tal entre a filosofia e o Direito a ponto de se conseguir restringir o problema do fundamento dos direitos humanos a um consenso obtido por meio de valores universalmente aceitos e consubstanciados por documentos internacionais, em especial a Declaração Universal de Direitos Humanos. Em outras palavras, trata-se de saber se é possível operar tal cisão entre aplicação/proteção e fundamentos dos direitos humanos. E a questão é importante porque, embora seja possível afirmar uma unanimidade no âmbito da comunidade jurídica no que se refere a necessidade de proteção da dignidade humana, tanto na esfera internacional quanto nacional, saber qual é a abrangência de cada direito humano, ou fundamental, permanece um problema para o qual ainda não existem respostas que se candidatem a fundar um consenso no ambiente doutrinário. E é nesse aspecto que se apresenta a insuficiência das teorizações do próprio Norberto Bobbio para a resolução desse problema. É significativo o fato de o teórico italiano assumir ser Hans Kelsen seu teórico do Direito por excelência (BOBBIO, 2010, p. 11), pois o positivismo jurídico em sua vertente normativista ${ }^{1}$ é precisamente ponto de estofo da cisão entre a ciência do Direito e outras áreas do conhecimento.

A pretensão de Kelsen (2009, p. 1), ao definir sua teoria como "pura", era justamente a de delimitar o objeto do conhecimento jurídico eliminando dele tudo o que não se possa rigorosamente ser definido como "Direito". O recurso utilizado pelo autor austríaco para a concretização de seu objetivo se sucede através da divisão do Direito em dois níveis de linguagem. O primeiro deles refere-se aos meios pelos quais é possível a interpretação de determinados fenômenos, operando as normas jurídicas como uma verdadeira linguagem da realidade na medida em que são a condição de possibilidade para a qualificação de um determinado fato como jurídico, produzindo enunciados prescritivos. O segundo nível, de metalinguagem, é quando as próprias normas passam a ser objeto de estudo do cientista do Direito. Nessa segunda etapa, as asserções caracterizam-se por serem descritivas (ROCHA, 2005, p. 72).

Delimitada a atribuição da ciência jurídica (estabelecida pelo segundo nível de metalinguagem acima exposto), cabia ainda a definição de seu objeto, ou seja, no que consistiria aquela metalinguagem de primeiro nível. Tanto em Bobbio quanto em Kelsen, a ideia de norma jurídica está estreitamente ligada à noção de sanção, contudo, para o autor italiano, há uma diferença entre ambas as concepções. Entende ele que a conceituação kelseniana de norma jurídica é demasiadamente restritiva por adotar como critério seu conteúdo: regra jurídica é a disposição acerca de uma sanção (BOBBIO, 2010, p. 228-230). Para Bobbio, somente uma ótica formal para a definição de norma jurídica poderia ser capaz de fornecer um conceito suficientemente amplo para abarcar todas as prescrições que se encontram no interior de um ordenamento jurídico e, ao mesmo tempo, suficientemente fechado para conseguir diferenciar o Direito dos demais sistemas sociais. Com base em tal pressuposto, o jurista de Turim define norma jurídica como

\footnotetext{
Adota-se, neste trabalho, a distinção feita por Streck (2011) do positivismo jurídico em três momentos: o primeiro deles era caracterizado pela defesa de um objetivismo dedutivista como controle rigoroso da racionalidade jurídica, sendo suas escolas mais conhecidas a exegese, na França, e o pandectismo, na Alemanha; subsequentemente, com o declínio de tais posturas e como reação à emergência de outras correntes de pensamento que procuravam expandir o campo de investigação do Direito introduzindo elementos de outras áreas científicas, o positivismo normativista reconhece a indeterminação do fenômeno jurídico e, por isso, advoga uma acentuada ruptura entre o mundo prático, tido como eivado pelo subjetivismo do intérprete e impossível de ser apreendido cientificamente; e a razão teórica, a qual delimitaria o âmbito do conhecimento jurídico a elaboração de enunciados descritivos acerta da metalinguagem objeto, o ordenamento jurídico. O expoente mais conhecido desta perspectiva é Hans Kelsen. Finalmente, o neopositivismo (ou neoconstitucionalismo) que tem como proposta a superação de ambos os modelos anteriores pela tese de que por "trás" dos textos normativos nacionais encontram-se valores da sociedade, os quais podem ser descobertos pelo voluntarismo interpretativo. (STRECK, 2011, p. 119).
} 
aquela proposição prescritiva de uma conduta "cuja execução é garantida por uma sanção externa e institucionalizada" (BOBBIO, 2010, p. 152).

Todavia, tanto para Kelsen quanto para Bobbio, a sanção não é a única característica de uma norma jurídica, pois ela deve também pertencer a um ordenamento, ou seja, um conjunto de normas que se relacionam harmonicamente entre si, o que é distintivo das normas do Direito. Para Kelsen (2009, p. 215), uma norma jurídica somente pode ser considerada válida na medida em que seja elaborada conforme o comando de outra norma hierarquicamente superior, e esta, por sua vez, também encontra sua validade em outra norma de escalão superior. Com efeito, a pergunta sobre a validade de uma norma jurídica não poderia resultar em um regresso ad infinitum. Para evitar tal problema e simultaneamente estabelecer o fechamento do ordenamento jurídico, a teoria kelseniana recorre a uma norma fundamental a qual todas as demais remetem, mesmo que mediatamente. A norma fundamental, entretanto, não empresta validade às demais normas jurídicas por conta de algum conteúdo que possa ser considerado como autoevidente por uma determinada sociedade (KELSEN, 2009, p. 217), pois ela é tão somente hipotética e pressuposta na validade das demais normas, possuindo um caráter eminentemente formal para o fechamento do ordenamento jurídico (BOBBIO, 2006, p. 203).

Assim, a norma fundamental se constitui como um mecanismo procedimental de fundamentação do ordenamento jurídico e delimitação daquilo que o integra, diferenciando o Direito de outros sistemas sociais baseados em normas, como a moral. Há, portanto, uma separação entre a validade e o conteúdo do ordenamento jurídico, uma vez que aquela não é considerada sob um prisma material, mas tão somente formal, o que fica bastante claro quando Bobbio (2010, p. 223) afirma que a única resposta possível àqueles que desejem saber qual é o fundamento da norma fundamental é "sair" do sistema normativo do Direito em direção a outros objetos de investigação, logo não se tratando mais de um problema jurídico.

Bobbio (2010) procura, por meio dessa arquitetura teórica normativista, fornecer um mecanismo de proteção aos direitos humanos relegando a questão dos fundamentos da filosofia e, portanto, fora do ordenamento jurídico, uma vez que o critério de validade neste, como visto, é meramente formal. Ocorre que, com a ambição normativista de depuração do objeto da ciência jurídica, não havia espaço para a teoria do Direito se preocupar com aplicação das normas no âmbito pragmático, no que diz respeito a um critério de correção. Como consequência, o "caso concreto" também era visto sob uma perspectiva eminentemente descritiva, pois não existiriam recursos teóricos suficientemente eficazes de exercer controle da aplicação prática desse mesmo ordenamento jurídico (STRECK, 2013a, p. 69 e ss). É ilustrativo dessa aporia na qual se encontrava preso o positivismo jurídico a afirmação de Kelsen de que a questão de saber qual seja a interpretação correta de uma norma, dentre as várias possíveis, não é um problema de teoria do Direito, mas um problema de política do Direito (KELSEN, 2009, p. 393).

Contudo, esse recorte epistêmico do qual se vale Bobbio sob nenhuma hipótese é capaz de fornecer uma proteção jurídica aos direitos humanos. Dizer que a partir da Declaração de 1948 se constituiu um consenso internacional acerca de determinados valores tidos como universalmente aceitos apenas aprisiona o fenômeno na semântica, originando uma visão ocidental universalista e ingênua dos direitos humanos. Embora se possa aceitar existência de um consenso no que se refere, por exemplo, a um direito de o réu ser presumidamente inocente no processo penal - veja-se que, na decisão do Habeas Corpus 128.292/SP, conhecido pelo posicionamento do Supremo Tribunal Federal em permitir a execução antecipada da pena ao réu condenado em segunda instância, nenhum ministro da corte questionou a existência desse direito, apenas se discutiu seu âmbito de incidência - o positivismo jurídico normativista não consegue fornecer, e tampouco se preocupa em fazê-lo, uma teorização acerca da correção da aplicação desse direito, logo esse mesmo consenso não se estende ao conteúdo da norma, o qual somente pode ser recuperado pela via de seu fundamento - considerado sob uma perspectiva intersubjetiva, como se verá no tópico seguinte -, pois, do contrário, fica à mercê da discricionariedade do intérprete.

Mas o positivismo jurídico normativista também implica outra dificuldade: sua teoria do ordenamento jurídico resulta em uma cisão entre direitos fundamentais - incorporados pelo sistema normativo interno 
de um Estado - e os direitos humanos - reconhecidos em âmbito internacional, mas não necessariamente absorvidos pelos ordenamentos jurídicos nacionais - sustentando uma dicotomia de caráter eminentemente formal em detrimento do conteúdo de ambos. A preocupação com questão de saber qual a posição das normas relativas aos direitos humanos no interior de um sistema normativo nacional conforme um escalonamento hierárquico muitas vezes esconde o fato de que, contemporaneamente, os Estados somente podem se constituir como democracias quando respaldados por um compromisso solidário internacional de proteção da dignidade humana. Em outras palavras, não há democracia desvinculada de um conteúdo mínimo estabelecido pelos direitos humanos (FERREIRA, 2016, p. 38). Tais hierarquizações são ainda mais difíceis na Constituição Federal brasileira de 1988, especialmente em razão do que dispõe seu $\S 2^{\circ}$ do art. $5^{\circ}$, o qual deixa claro que o rol de direitos expressos pelo próprio texto constitucional não exclui outros decorrentes dos tratados internacionais do qual o país faça parte.

Talvez o imbróglio envolvendo o status hierárquico-normativo desses direitos advindos de tratados internacionais dos quais o Brasil faz parte seja uma das mais enfáticas demonstrações de esgotamento do positivismo normativista para fornecer as respostas demandadas pela complexidade dos Direitos Constitucional e Internacional Público contemporâneos. Por um considerável período de tempo, o posicionamento do Supremo Tribunal Federal era o de que as normas de tratados de direitos humanos que ingressavam no ordenamento jurídico brasileiro por força do $\S 2^{\circ}$ do art. $5^{\circ}$ da Constituição Federal o faziam na condição de legislação ordinária. ${ }^{2}$ Mas o entendimento da Corte não fora satisfatório para aplacar a controvérsia no âmbito doutrinário ${ }^{3}$, de modo que veio a ser promulgada a Emenda Constitucional $n^{\circ} 45 / 2005$, a qual acrescentou o $\S 3^{\circ}$ ao art. $5^{\circ}$ da Constituição Federal, estipulando que os tratados de direitos humanos aprovados em dois turnos por três quintos dos membros de cada uma das casas do Congresso Nacional passariam a ser equiparados às normas constitucionais. Diante do dissenso produzido pela interpretação do $\S 2^{\circ}$ do mesmo artigo, foi criada uma meta-regra (contida no $\S 3^{\circ}$ ) como tentativa de solucionar a controvérsia.

Com efeito, a discussão ainda não havia se encerrado com a edição do $\S 3^{\circ}$ do art. $5^{\circ}$ da Constituição Federal. Antes o contrário: agravou-se em virtude da dificuldade em saber qual seria o status no interior do ordenamento jurídico dos tratados de direitos humanos assinados pelo Brasil antes da promulgação da Emenda Constitucional de $n^{\circ} 45$, e qual o grau hierárquico daqueles documentos internacionais que, mesmo após a emenda, não houvessem passado pelo procedimento legislativo exigido para sua equiparação às normas constitucionais. ${ }^{4}$ No intuito de novamente buscar uma resolução para tais controvérsias, o Supremo Tribunal Federal, no julgamento do Recurso Extraordinário $n^{\circ} 466.343$, influenciado pelo eloquente voto do ministro Gilmar Mendes, passou a endossar um tertium genus: os tratados de direitos humanos não compreendidos pelo $\S 3^{\circ}$ do art. $5^{\circ}$ da Constituição Federal deveriam ingressar não na condição legal, ou constitucional, mas sim supralegal e infra-constitucional.

Criou-se então, a pretexto de preservação da soberania do Estado, uma divisão entre normas de direitos humanos incorporadas pelo rito legislativo do $\S 3^{\circ}$ do art. $5^{\circ}$ da Constituição Federal, equiparados a normas constitucionais, e os tratados de direitos humanos recepcionados apenas pelo $\S 2^{\circ}$ do mesmo dispositivo, os quais possuiriam status somente supralegal. Em outras palavras, o §3 não cuidou de ser

Esse entendimento foi firmado em diferentes oportunidades, dentre as quais podem ser mencionados, a título exemplificativo, os julgamentos do Habeas Corpus $n^{\circ} 72.131$ e do Recurso Extraordinário de $n^{\circ} 206.482$ pelo Supremo Tribunal Federal.

3 Francisco Rezek, em 1997, já manifestava inconformidade com o entendimento do Supremo Tribunal Federal sobre o Pacto de San José da Costa Rica: "[...] E perplexo, quase a crer que minhas faculdades mentais já se perdiam àquela altura da vida, dei-me conta de que alguém estava ali raciocinando como se a Convenção de São José da Costa Rica fosse um produto que por obra nefanda de alienígenas desabasse sobre a nossa cabeça, à nossa revelia, como se aquilo não fosse um pleno exercício de legislação ordinária, como se pudesse o texto de São José valer para nós se o Congresso Nacional não o tivesse aprovado, e se o Presidente da República não o tivesse ratificado. Parece que não se sabe ainda, aqui ou ali, que o Direito Internacional Público não é uma imposição de criaturas exóticas a nossa brasilidade. Não. Ele não existiria se não fosse nossa obra comum com outros povos" (REZEK, 1997, p. 226).

4 Esse problema foi abordado, por exemplo, por Celso Lafer (2005, p. 15-16), para quem os tratados internacionais de direitos humanos pré Emenda Constitucional $n^{\circ} 45 / 2005$ seriam incorporados na condição de normas constitucionais por força somente do $\S 2^{\circ}$ do art. $5^{\circ}$ da Constituição Federal, enquanto os documentos cuja adesão brasileira tenha sido posterior à referida emenda precisam passar pelo procedimento previsto pelo $3^{\circ}$ do mesmo art. $5^{\circ}$ 
apenas de uma tentativa de solucionar uma controvérsia no âmbito doutrinário, mas também de limitar a incidência do $\S 2^{\circ}$. Portanto, não surpreendem as críticas dirigidas ao dispositivo introduzido pela Emenda Constitucional $n^{\circ} 45 / 2005$ sob o argumento de que ela significou uma fragilização dos compromissos do Estado brasileiro com os direitos humanos em prol de um formalismo exacerbado. ${ }^{5}$

Naquilo que concerne a este trabalho, é possível sumarizar que a introdução do $\S 3^{\circ}$ do art. $5^{\circ}$ da Constituição Federal foi fomentada muito mais pela questão de saber qual seria o status hierárquico normativo dos tratados de direitos humanos do que sobre as possibilidades de concretização de um compromisso com a efetivação de um projeto internacional de proteção da dignidade humana a partir do diálogo entre os Direitos Constitucional e Internacional Público. É dizer: a preocupação com a efetividade dos direitos humanos a partir de sua incorporação pelo Direito brasileiro transformou-se no fetiche pela posição dos tratados internacionais de direitos humanos no interior do ordenamento jurídico brasileiro. Essa decaída qualitativa na discussão é caudatária da ideia de uma necessidade de buscar o fundamento das normas internacionais a partir de um critério eminentemente procedimental, de validade no plano interno; afinal, se o $\S 2^{\circ}$ do art. $5^{\circ}$ da Constituição Federal estendeu o rol de direitos e princípios constitucionais para além daqueles reconhecidos no catálogo do texto, foi preciso outra disposição estabelecendo um procedimento legislativo específico para afirmar a validade constitucional daquilo que venha a ser incorporado.

Cabe destacar que, tanto o problema da validade dos direitos humanos no ordenamento jurídico interno quanto o decorrente da falta de um critério de correção sobre a sua incidência, estão relacionados e implicam uma visão compartimentada sobre o fenômeno. Afinal, seria cabível indagar se é possível compreender qualquer um dos direitos fundamentais, mesmo os oriundos do texto originário da Constituição, sem remissão a uma afirmação histórica desses mesmos direitos no âmbito internacional. Há, portanto, uma implicação mútua entre direitos humanos (incorporados ou não) e direitos fundamentais, pois estes não são autóctones, apesar de serem interpretados conforme as particularidades de cada sociedade concreta. Eis o ponto que aqui se torna central, e cuja solução somente pode ser encontrada quando forem percebidas as limitações do positivismo jurídico: como conciliar a validade e a legitimidade dos direitos humanos sem precisar recorrer a critérios procedimentais que impeçam a realização do diálogo entre as perspectivas nacionais e internacionais de proteção da pessoa humana? O próximo tópico se dedicará a apontar algumas possibilidades pensadas a partir da hermenêutica filosófica.

\section{Um caminho possível para a superação da inautêntica dualidade entre fundamentos e proteção dos direitos humanos a partir da hermenêutica filosófica e do direito como integridade}

Do que foi exposto acima, a proposta do positivismo jurídico normativista, expressa, neste trabalho, pela construção sobretudo de Norberto Bobbio, ocasiona pelo menos dois constrangimentos que, na teoria do Direito contemporâneo precisam ser resolvidos, e ambos relacionados ao problema da distinção entre fundamentos e validade dos direitos humanos. O primeiro deles, como já referido, é saber se é possível distanciar o seu fundamento de sua aplicação/proteção. A segunda questão está relacionada sobre ser também razoável uma diferenciação eminentemente formal ente direitos humanos e fundamentais como mecanismo de averiguação da incorporação pelo ordenamento jurídico interno de um país dos primeiros na condição dos últimos. A ideia central que será defendida neste tópico é que não se pode pensar contemporaneamente a validade do próprio Direito desconexa da construção histórica dos direitos humanos, sob pena de se retornar a uma teoria jurídica preocupada e apta a resolver tão só problemas epistemológicos. Para esse desiderato, vale-se da abordagem proporcionada pela hermenêutica filosófica e pelo Direito como integridade como caminhos possíveis a serem trilhados na superação da herança positivista de fazer/pensar o Direito.

\footnotetext{
5 Por todos, Cançado Trindade (2016, p.410-411) afirma ser a introdução do $\S 3^{\circ}$ do art. $5^{\circ}$ "um retrocesso provinciano que coloca em risco a interrelação ou indivisibilidade dos direitos protegidos em nosso país (previstos nos tratados que o vinculam), em favor de excessos de um formalismo e hermetismos jurídicos".
} 
O primeiro pressuposto a ser desenvolvido é o de que o Direito é uma construção artificial, ainda que procure buscar seus fundamentos no plano existencial (CARNEIRO, 2015, p. 145).

\begin{abstract}
Nessa busca nos colocamos diante de um grande desafio, uma vez que a opção pelo Direito não nos retira nossa condição existencial e, consequentemente, não imuniza nossa compreensão de antecipações de sentido de ordem moral. A opção por uma estrutura sistêmica artificial não nos coloca isolados na artificialidade. Além disso, como se não bastasse essa confusão existencial entre direito e moral, o direito não é autossuficiente. Isso quer dizer que, mesmo se conseguíssemos por uma vigilância reflexiva imunizar nossos prejuízos de moralidade, não conseguiríamos nos movimentar exclusivamente no direito, já que sua artificialidade não conferiria resposta a todos os problemas. [...] Direito e moral são co-originários se analisarmos a relação entre ambos por uma perspectiva hermenêutica, já que o sentido moral-prático de um problema sempre se antecipará mesmo antes de buscarmos uma resposta exclusivamente jurídica para ele (CARNEIRO, 2015, p. 147. Grifos no original).
\end{abstract}

Essa co-originariedade entre Direito e moral, responsável por fazer com que o sujeito sempre antecipe um sentido diante de um problema onde o Direito precisa ser interpretado, evidentemente não significa que a moral venha a substituir o Direito a partir de um juízo subjetivista do intérprete. O pressuposto aqui é que o mundo é compartilhado intersubjetivamente, de modo que não há racionalidade em estado puro, somente sendo possível realizar um enunciado assertórico predicativo por meio de uma estrutura prévia de sentido (STEIN, 2010, p. 19). Os prejuízos do intérprete são, portanto, condição de possibilidade para que ele tenha acesso às coisas, e caso se pretenda pensar no controle da subjetividade do intérprete, deve-se colocar em questão uma das principais reivindicações do positivismo normativista: a separação entre um conhecimento jurídico e a moral, isto é, como há sempre algo que se antecipa ao sujeito, caso se pretenda pensar em respostas corretas no âmbito jurídico, faz-se necessário superar a distinção entre os mundos prático e teórico (STRECK, 2013a, p. 64-65).

A Teoria do Direito deve, então, se preocupar com essa antecipação de um sentido moral-prático do intérprete. $E$ isto, ao menos para o que aqui vem sendo trabalhado, tem implicações importantes, especialmente no que diz respeito à legitimidade do Direito: se há esta antecipação que é fruto de um processo compartilhado de atribuição de sentido às coisas, não é mais possível pensar o problema da validade dissociado do da legitimidade. Assim sendo, além dos critérios formais de validade de um dado provimento, é preciso que haja o engajamento por parte da comunidade política de que sua aplicação/ interpretação seja correta, pois, do contrário, haveria uma recaída no relativismo, o qual sempre deixa o Direito refém de uma racionalidade instrumental que o subjuga a diferentes interesses e jogos de força, sejam eles políticos, sejam econômicos, sejam até mesmo morais. A questão que se coloca é precisamente como fundar um conhecimento jurídico capaz de dar conta dessa antecipação de sentido e, simultaneamente, preservar o Direito de um niilismo que esconde a intersubjetividade presente na construção do fenômeno jurídico.

Uma das maiores contribuições dadas para solucionar essa dificuldade foi elaborada por Ronald Dworkin (2010). Para o teórico estadunidense, o Direito expressa diferentes dimensões de uma mesma moralidade política, a qual deve manter sua coerência e integridade reconhecendo que todos os membros de sua comunidade são dignos de igual consideração e respeito. Há, então, uma responsabilidade política, a qual "afirma que as autoridades políticas devem tomar somente as decisões políticas que possam justificar no âmbito de uma teoria política que também justifique as outras decisões que elas se propõem a tomar" (DWORKIN, 2010, p. 137). Impõe-se, logo, o entendimento da comunidade política como um ente personificado capaz de assumir compromissos, projetos e ideais junto a seus membros, devendo agir de acordo com um conjunto único e coerente de princípios, mesmo quando os cidadãos possam estar divididos quanto aos princípios de justiça e equidade corretos que devem ser aplicados (DWORKIN, 2007, p. 204).

Um romance em cadeia é a metáfora da qual se vale Dworkin para ilustrar melhor a assertiva segundo a qual todas as decisões políticas precisam encontrar respaldo em um todo íntegro e coerente de princípios. Por ela, cada intérprete é responsável por escrever um capítulo de uma obra coletiva com outros 
intérpretes. Tal qual um romance, esta obra não pode possuir em seus capítulos elementos destoantes e contraditórios. E, como cada autor recebe a obra em grande parte já desenvolvida, precisa recuperar seus elementos centrais para conseguir desenvolver sua contribuição, bem como estabelecer outros componentes que também sejam possíveis de serem resgatados pelos escritores dos próximos capítulos.

Decidir casos controversos no Direito é mais ou menos como esse estranho exercício literário. [...]. Cada juiz, então, é como um romancista na corrente. Ele deve ler tudo o que outros juízes escreveram no passado, não apenas para descobrir o que disseram ou seu estado de espírito quando o disseram, mas para chegar a uma opinião sobre o que esses juízes fizeram coletivamente, de maneira como cada um de nossos romancistas formou uma opinião sobre o romance coletivo escrito até então (DWORKIN, 2005, p. 283).

Mas o que deve ser resgatado dessa tradição histórica do Direito pelo intérprete responsável por escrever um dos capítulos do romance? Aqui, a ideia de princípio é central: Dworkin pretende mostrar que os juízes não fazem apenas uma subsunção do fato concreto à regra jurídica, como as abordagens mais usuais pretendiam. Ao decidir uma determinada causa, muitas vezes valem-se os magistrados de outras espécies de argumentos que direcionam a discussão em um ou outro sentido (DWORKIN, 2010, p. 36). Quando tais argumentos são políticos, caracterizam-se por sua estrutura teleológica, alegando que, ao decidir conforme sua orientação, se está perseguindo melhor um determinado objetivo ou melhorando o bem-estar geral de uma determinada população (DWORKIN, 2010, p. 36). Os princípios, em sentido estrito, por outro lado, são argumentos de um padrão que deve ser observado "não por conta de promover ou assegurar uma situação econômica, política ou social considerada desejável, mas porque é uma exigência de justiça, equidade ou alguma outra dimensão da moralidade" (DWORKIN, 2010, p. 36. Grifamos). Para o autor estadunidense, como parece ter ficado claro, princípios não são critérios de decisão finalísticos, mas padrões deontológicos que vão sendo firmados ao longo da história de uma comunidade porque melhor expressam os diferentes compromissos, os objetivos e ideais assumidos por essa mesma comunidade com seus membros. O Direito, por fim, deve ser visto como o foro do princípio, pois é ele que garante que seja a justiça uma "uma questão de direito individual, não, isoladamente, uma questão de bem público" (DWORKIN, 2005, p. 39).

Cabe aqui frisar a aproximação entre as teses de Ronald Dworkin e a hermenêutica filosófica de Hans-Georg Gadamer e suas respectivas consequências para o Direito. Se há sempre um sentido moral-prático que o sujeito antecipa na interpretação do fenômeno jurídico, tal não significa que seja impossível ao intérprete tomar conhecimento de seus próprios pré-juízos. Antes o contrário: o esforço de interpretação implica uma revisão constante para evitar o arbítrio dos preconceitos e possibilitar a alteridade (GRONDIN, 1999, p. 165). Isto não significa que Gadamer acredite ser possível alcançar um conhecimento "objetivo", oriundo exclusivamente da razão. Tal oposição entre razão e tradição é vista como caudatária de uma herança cartesiana, a qual rechaça toda a verdade que não esteja fundada em uma causa última (GRONDIN, 2009, p. 69). Para a hermenêutica filosófica há sempre uma cumplicidade entre o sujeito e o objeto, pois toda compreensão se sucede através de uma estrutura prévia de sentido mediada pela linguagem responsável por dar acesso ao mundo para o sujeito (STEIN, 2010, p. 45 e ss). Assim, a preocupação gadameriana é saber como ocorre a compreensão através da qual alguém consegue apreender o sentido e a perspectiva daquilo que é transmitido no seio de uma tradição compartilhada com outros indivíduos. A tradição é o lugar comum que determina as antecipações e orienta a compreensão dos sujeitos (GADAMER, 2003, p. 59).

Quem quiser compreender um texto realiza sempre um projetar. Tão logo apareça um primeiro sentido no texto o intérprete prelineia um sentido todo. [...] A compreensão do que está exposto no texto consiste precisamente na elaboração desse projeto prévio, que, obviamente, tem que ir sendo constantemente revisado com base no que se dá conforme se avança na penetração do sentido.

Essa descrição é, naturalmente, uma abreviação rudimentar: o fato de que toda revisão do projeto prévio está na possibilidade de antecipar um novo projeto de sentido; que projetos rivais possa se colocar lado a lado na elaboração até que se estabeleça uma univocidade de sentido; que a interpretação comece com conceitos prévios que serão substituídos por outros mais adequados [...] 
Quem procura compreender está exposto ao erro de opiniões prévias, as quais não se confirmam nas próprias coisas. Elaborar projetos corretos e adequados às coisas, que como projetos são antecipações que apenas devem ser confirmadas 'nas coisas', tal é a tarefa constante da compreensão. Aqui não existe outra 'objetividade' que a confirmação que uma opinião prévia obtém através de sua elaboração. [...] A compreensão somente alcança sua verdadeira possibilidade, quando as opiniões prévias, com as quais ela inicia, não são arbitrárias. Por isso faz sentido que o intérprete não se dirija aos textos diretamente, a partir da opinião prévia que lhe subjaz, mas que examine tais opiniões quanto à sua legitimação, isto é, quanto à sua origem e validez (GADAMER, 1997, p. 402-403).

É perceptível, então, que não há espaços para relativismos tanto no Direito como integridade quanto na hermenêutica. Tanto em um como no outro é possível distinguir prejuízos autênticos e inautênticos, legítimos e ilegítimos (STRECK, 2015, p. 169). Interpretar o Direito é escrever um novo capítulo de um romance em cadeia, mas, para esse desiderato, é preciso ler o material que já foi escrito. Nessa leitura, projetos de sentido rivais vão sendo confrontados em seu decorrer até que se torne possível estabelecer uma univocidade de sentido. Em outras palavras, o sentido moral-prático que se antecipa ao sujeito na compreensão de um caso concreto é sempre algo que pode ser revisto a partir da tradição histórica firmada pela moralidade política de uma comunidade. Embora essa possibilidade fique bastante clara nos usualmente chamados "hard cases", ela é frequentemente velada nos "easy cases", não porque se mostre desnecessária, mas porque nessas hipóteses o intérprete possui uma resposta antes mesmo de a pergunta ser formulada (FERREIRA, 2013, p. 96-97), por isso também fracassam as tentativas de isolar o fenômeno jurídico da realidade prática recorrendo-se a métodos dedutivos no intuito de controlar a subjetividade. A subsunção, proposta mais difundida dessas tentativas, nada mais faz do que possibilitar o subjetivismo do intérprete ao recepcionar acriticamente suas preconcepções como um sentido intrínseco ao texto. ${ }^{6}$

Talvez agora fique claro porque, diferentemente do que propôs Bobbio, não é possível colocar o problema da fundamentação em um segundo plano, ou ainda deslocá-lo como um problema exclusivamente de filosofia política, enquanto a proteção dos direitos humanos ficaria sob encargo do Direito, ou da política em um sentido mais amplo. Não é possível operar essa distinção uma vez que a própria interpretação implica sempre um processo de aplicação, isto é, de atribuição de sentido. Caso esse sentido se pretenda autêntico, ele precisa retomar a história institucional da comunidade política na qual se situa para possibilitar ao intérprete enfrentar seus pré-juízos e construir uma compreensão intersubjetiva acerca do Direito. Uma coisa, todavia, é certa: se os argumentos de princípio inferem que um determinado padrão deve ser observado, mesmo que se oponha a um objetivo comum, por conta de uma dimensão de moralidade política, eles não podem ser relativizados frente a argumentos finalísticos (STRECK, 2013b, p. 260-261), pois, do contrário, o Direito abriria mão de ser o foro do princípio, posição que permite ao Poder Judiciário ser um fator contra-majoritário no decorrer da vida política de um país, para se tornar uma racionalidade instrumental a serviço do poder político.

Fundamentação e aplicação estão, pois, implicados reciprocamente: não é possível abrir mão de um sem, ao mesmo tempo, abdicar de refletir sobre o outro. É por isso que também deve ser problematizada a discussão formalista envolvendo a recepção dos tratados internacionais de direitos humanos na condição supralegal, ou equiparados a emendas constitucionais, conforme se enquadrem na regulamentação dos $\S \S$ $2^{\circ}$ e $3^{\circ}$ do art. $5^{\circ}$ da Constituição, respectivamente. Ora, se o compreender implica sempre um resgate da tradição autêntica, então sempre que se falar em direitos fundamentais é preciso vir a lume toda a tradição de afirmação histórica dos Direitos Humanos, para usar a expressão de Comparato (2007). Os direitos fundamentais não são categorias monádicas que, em algum momento, passaram a ser incorporados e vistos como dignos de proteção nos regimes democráticos. Trata-se antes de um processo cujas

\footnotetext{
6 Vários autores brasileiros reconhecidos nacionalmente entendem ser possível essa distinção semântico-estrutural entre easy e hard cases, especialmente os filiados às teorias argumentativas de matriz alexyana, dos quais respeitosamente diverge este trabalho. Por todos cite-se: Barroso (2011, p. 381).
} 
raízes podem ser encontradas desde as escolas jusnaturalistas, antes mesmo da positivação da própria Declaração Universal dos Direitos Humanos. Não se trata de serem buscados fundamentos últimos para os direitos humanos a partir do Direito Natural, mas de retomar o processo histórico de sua construção como compromissos voltados para a proteção da pessoa humana diante das mais variadas ameaças e violências contra ela cometidas ao longo da história (FERREIRA, 2016, p. 286 e ss).

A Declaração Universal de Direitos Humanos é um marco importante neste retrospecto, trazendo consigo uma perspectiva crítica e uma tradição histórica que orientaram os movimentos constitucionais, após a segunda metade do século XX, a incorporarem em seus textos, na forma de direitos fundamentais, todo o feixe moral normativo dos direitos humanos. Assim, a positivação dos destes na ordem interna dos Estados deve ser vista como uma consequência do movimento histórico de constitucionalização que se articulava junto a um processo internacional de proteção do ser humano após a Segunda Guerra Mundial. É preciso reconhecer, logo, que a positivação interna dos direitos humanos não implicou uma transformação "genética", senão meramente linguística, a qual não afeta a substancialidade dos compromissos exigíveis do Estado Democrático de Direito (FERREIRA, 2016, p. 298). Sob esta ótica, percebe-se que o próprio fenômeno Constituição fertiliza e, ao mesmo tempo, é fertilizado pelo Direito Internacional dos direitos humanos, pois um não pode ser compreendido sem o outro (FERREIRA, 2016, p. 279), sendo insuficiente, para não dizer até mesmo inadequado, se falar em supralegalidade nesta seara.

Frente a tal cenário, a exigência de um rito específico para a equiparação dos tratados internacionais de direitos humanos a normas constitucionais parece ser apenas consequência de uma visão monádica acerca do que sejam direitos fundamentais. Aliás, os próprios $\S \S 1^{\circ}$ e $2^{\circ}$ do art. $5^{\circ}$ da Constituição Federal consubstanciam a tradição constitucional vinculada à afirmação histórica dos direitos humanos, por isso a regra do $\S 3^{\circ}$, a pretexto de produzir maior segurança e estabilidade jurídica, representa uma ótica monológica, tanto de constitucionalismo quanto de direitos fundamentais, como se ambos os fenômenos pudessem ser ocorrências autóctones que apenas coincidentemente possuiriam elementos centrais em comum para a consolidação de seus regimes democráticos. A própria constitucionalidade do $\S 3^{\circ}$ do art. $5^{\circ}$ merece então ser questionada, seja por questões estruturais dentro do texto constitucional (não há espaço para "equiparações" a normas constitucionais dentro de nosso sistema jurídico), seja por fundamentos de coerência (como seria possível o reconhecimento da jurisdição do Tribunal Penal Internacional pelo $\S 4^{\circ}$ do mesmo artigo e, ao mesmo tempo, adotar uma postura diametralmente oposta com relação à aplicabilidade imediata dos tratados de direitos humanos?), seja por elementos substanciais (ao desvincular o conteúdo constitucional do Direito Internacional Público por meio da dicotomia direitos humanos/fundamentais) (FERREIRA, 2016, p. 303 e ss).

A exposição realizada acima não esgota o debate acerca da implicação entre constitucionalismo e direitos humanos. Outras questões precisam ainda ser enfrentadas, como a relativa à soberania dos Estados e à competência dos diversos tribunais internacionais de direitos humanos para reformar ou endossar as decisões proferidas pelo Supremo Tribunal Federal. Mas tais indagações precisariam de maior espaço e fogem do foco desenvolvido por este trabalho. Não obstante, aquilo que se espera é poder ter convencido o leitor de que não é possível deslocar o problema do fundamento dos direitos humanos para um lócus de investigação, exclusivamente, filosófico, porque sua própria proteção/aplicação implica sempre a retomada de um projeto lançado pelo intérprete na tentativa de reconstruir a história institucional de sua comunidade política, com o objetivo de empreender uma interpretação autêntica da Constituição e dos próprios tratados internacionais de direitos humanos. Tal constatação implica ainda ser impossível compreender a relação entre constitucionalismo e direitos humanos somente através de uma estrutura escalonada de normas jurídicas. Como já dito, não é possível pensar o fenômeno constitucionalismo desvinculado dos movimentos internacionais pós Segunda Guerra Mundial, voltados para a proteção da dignidade humana. Há uma coimplicação de conteúdo entre os direitos humanos e fundamentais, de modo que a distinção entre uns e outros é apenas formal, ou ainda linguística. Com isso, não se pretende defender um objetivismo universalista sobre a matéria. Cabe a cada sociedade buscar articular os direitos humanos com sua respectiva realidade concreta, levando em consideração a coerência e a integridade do 
Direito. Somente assim se torna possível pensar sua proteção sem se recorrer a expedientes formalistas/ positivistas, os quais ignoram, ou não conseguem dar conta, de um mundo histórico compartilhado intersubjetivamente.

\section{Conclusão}

O constitucionalismo contemporaneamente significou um marco dos regimes democráticos comprometidos com o impulsionamento dos direitos humanos. Se é possível considerar isso como um avanço, no entanto, é preciso também sublinhar um acréscimo de complexidade do fenômeno jurídico decorrente. Assim, revisitar as bases que muitas vezes estão subentendidas nos discursos doutrinários se torna uma tarefa importante para se vislumbrar tal acontecimento sem que os pré-juízos não reconhecidos influam no processo compreensivo, velando novas possibilidades a partir dos olhos do velho. Cindir os fundamentos dos direitos humanos de sua aplicação/proteção, como pretendia Norberto Bobbio, portanto, é um destes pressupostos que precisam ser urgentemente revistos pela comunidade jurídica brasileira. Como dito, não se pode cogitar uma interpretação visando concretizar um Direito que, dentro de um paradigma intersubjetivo e compartilhado de mundo, prescinda de uma reconstrução de seus pressupostos inscritos no âmbito de uma história institucional incorporada pela sua comunidade política. Para os direitos humanos tal proposição quer dizer que o seu significado somente pode ser alcançado quando discutidos seus fundamentos, estabelecendo um diálogo com a tradição hermenêutica na procura por interpretações que reivindiquem ser corretas por resultarem, justamente, da confrontação de diferentes projetos de sentido na tentativa de saber qual deles é o mais adequado para apanhar aquilo que cada direito possui de singular e próprio, sem serem assujeitados, portanto.

Os direitos positivados nos textos constitucionais, tradicionalmentedenominadoscomo "fundamentais", igualmente possuem um lastro substancial com os compromissos internacionais de proteção dos direitos humanos que não pode ser ignorado sem haver um déficit em sua compreensão. Como referido, no constitucionalismo pós Segunda Guerra, os direitos fundamentais passam a ser compreendidos como o alinhamento de alguns Estados a um movimento internacional de proteção à dignidade humana por meio de seus sistemas jurídicos internos. Dessa maneira, disjunções meramente semânticas, como a introduzida pelo $\S 3^{\circ}$ do art. $5^{\circ}$ da Constituição Federal, empobrecem aquilo que já vinha disposto nos $\S \S$ $1^{\circ}$ e $2^{\circ}$ do mesmo dispositivo, pois consubstanciam um imaginário que enxerga os diferentes movimentos constitucionais de cada sociedade como acontecimentos indiferentes uns aos outros.

Por fim, cabe sublinhar que, para o enfrentamento dessas dificuldades, faz-se preciso o reconhecimento de que a estrutura normativista de pensamento do Direito, de isolamento do mundo prático da teoria do Direito, precisa ser revista em direção ao reconhecimento de uma abordagem hermenêutica que consiga fornecer uma correta compreensão acerca do que seja uma interpretação, pois, do contrário, permaneceria o intérprete, sempre inadvertidamente, submetido a seus pré-juízos inautênticos em detrimento da democracia. Afinal, se o Direito é o foro do princípio, cabe sempre ao Judiciário exercer o papel contra-majoritário diante das maiorias eventuais que se formam no espaço dos Poderes representativos (Executivo e Legislativo), as quais podem, e não raras vezes o fazem, investir contra a realização dos direitos humanos, ameaça que não encontrará nenhuma resistência se o Direito for colonizado por argumentos de política.

\section{Referências}

ABBOUD, Georges. Processo constitucional brasileiro. São Paulo: Revista dos Tribunais, 2016.

BARROSO, Luís Roberto. Controle de constitucionalidade no direito brasileiro. 5. ed. rev. atual. São Paulo: Saraiva, 2011.

BOBBIO, Norberto. A era dos direitos. Tradução de Carlos Nelson Coutinho. Rio de Janeiro: Campus, 1992. 
BOBBIO, Norberto. Teoria geral do direito. Tradução de Denise Agostinetti. 3. ed. São Paulo: Martins Fontes, 2010.

BOBBIO, Norberto. O positivismo jurídico: lições de filosofia do Direito. Tradução de Marcos Pugliesi, Edson Bini e Carlos Rodrigues. São Paulo: Ícone, 2006.

CARNEIRO, Walber de Araújo. O Direito e as possibilidades epistemológicas do paradigma hermenêutico. In: STEIN, Ernildo; STRECK, Lenio Luiz (Org.). Hermenêutica e epistemologia: 50 anos de verdade e método. 2. ed. Rev. Porto Alegre: Livraria do Advogado, 2015. p. 147.

COMPARATO, Fábio Konder. A afirmação histórica dos direitos humanos. 5. ed. rev. atual. São Paulo: Saraiva, 2007.

DWORKIN, Ronald. Uma questão de princípio. Tradução de Luiz Carlos Borges. 2. ed. São Paulo: Martins Fontes, 2005.

DWORKIN, Ronald. O império do Direito. Tradução de Jefferson Luiz Camargo. 2. ed. São Paulo: Martins Fontes, 2007.

DWORKIN, Ronald. Levando os direitos a sério. Tradução de Nelson Boeira. 3. ed. São Paulo: WMF Martins Fontes, 2010.

FELLET, André; NOVELINO, Marcelo (Org.). Constitucionalismo e democracia. Salvador: Juspodivm, 2013.

FERREIRA, Rafael Fonseca. (A)crítica recepção das teses Alexyanas: o locus da discricionariedade judicial em terrae brasilis. Direitos fundamentais e justiça, Porto Alegre, ano 7, n. 27, p. 87-114, 2013. Disponível em: <http://www.dfj.inf.br/Arquivos/PDF_Livre/25_Doutrina_Nacional_03.pdf>. Acesso em: 09 mar. 2016.

FERREIRA, Rafael Fonseca. Internacionalização da constituição: diálogo hermenêutico, perguntas adequadas e bloco de constitucionalidade. Rio de Janeiro: Lúmen Juris, 2016.

GADAMER, Hans-Georg. Verdade e método - traços fundamentais de uma hermenêutica filosófica. Tradução de Flávio Paulo Meuer. 2. ed. Petrópolis: Vozes, 1997.

GADAMER, Hans-Georg. O problema da consciência histórica. Tradução de Paulo Cesar Duque Estrada. 2. ed. Rio de Janeiro: FGV, 2003.

GRONDIN, Jean. Introdução à hermenêutica filosófica. Tradução de Benno Dischinger. São Leopoldo: Unisinos, 1999.

GRONDIN, Jean. Hermenêutica. Tradução de Marcos Marcionilo. São Paulo: Parábola, 2012.

KELSEN, Hans. Teoria pura do direito. Tradução de João Baptista Machado. 8. ed. São Paulo: WMF Martins Fontes, 2009.

LAFER, Celso. A internacionalização dos direitos humanos: constituição, racismo e relações. Barueri: Manole, 2005.

REZEK, Francisco. Direito comunitário no Mercosul. Cadernos de Direito Constitucional e Ciência Política, Belém, v. 5, n. 18, p. 226-235, jan./mar. 1997.

ROCHA, Leonel Severo. Epistemologia jurídica e democracia. 2. ed. São Leopoldo: Unisinos, 2005. STEIN, Ernildo. Aproximações sobre hermenêutica. 2. ed. Porto Alegre: Edipuc, 2010.

STRECK, Lenio Luiz. Hermenêutica jurídica $\mathbf{e}(\mathbf{m})$ crise: uma exploração hermenêutica da construção do Direito. 10. ed. Porto Alegre: Livraria do Advogado, 2011.

STRECK, Lenio Luiz. O que é isto: decido conforme minha consciência? 4. ed. rev. Porto Alegre: Livraria do Advogado, 2013a.

STRECK, Lenio Luiz. O Supremo Tribunal Federal deve julgar por princípios ou por políticas? In: FELLET, André; NOVELINO, Marcelo (Org.). Constitucionalismo e democracia. Salvador: juspodivm, 2013b. p. 260-261. 
STRECK, Lenio Luiz. Hermenêutica e decisão jurídica: questões epistemológicas. In: STEIN, Ernildo; STRECK, Lenio Luiz (Org.). Hermenêutica e epistemologia: 50 anos de Verdade e Método. 2. ed. Rev. Porto Alegre: Livraria do Advogado, 2015.

TRINDADE, Antônio Augusto Cançado. Desafios e conquistas do direito internacional dos direitos humanos no início do século XXI. Nota 4. p. 410-411. Disponível em: <http://www.oas.org/dil/esp/407490\%20cancado\%20trindade\%200EA\%20CJI\%20\%20.def.pdf>. Acesso em: 20 ago. 2016.

Recebido em: 03/04/2017

Aprovado em: 16/02/2018 